PITCHIPOO PANDIAN, M.E., Ph.D.

Email: drpitchipoo@gmail.com

Department of Mechanical Engineering

P.S.R. Engineering College

Sivakasi, Tamil Nadu, India

VINCENT DEVANAYAGAM SUNDARAM, M.E.

Email: ds_vincent@yahoo.co.in

Tamil Nadu State Transport Corporation Ltd.

Thiruvannamalai, Tamil Nadu, India

RAJAKARUNAKARAN SIVAPRAKASAM, M.E., Ph.D.

Email: rajakarunakaran@klu.ac.in

Department of Mechanical Engineering

Ramco Institute of Technology,

RajapalayamTamil Nadu, India
Transport Engineering

Original Scientific Paper

Submitted: July 21, 2014

Approved: Feb. 2, 2016

\title{
DEVELOPMENT OF FUZZY BASED INTELLIGENT DECISION MODEL TO OPTIMIZE THE BLIND SPOTS IN HEAVY TRANSPORT VEHICLES
}

\begin{abstract}
Statistics reveals that the visual problems are the prime reasons for a larger number of road accidents. The blind spot is the major problem related to vision. The aim of this study is to develop a fuzzy-based multi criteria decision-making model for optimizing the area of the blind spot in the front and sides of a heavy transport vehicle. To achieve this, the statistical tool ANOVA (Analysis of Variance) and multi criteria optimization techniques like TOPSIS (Technique for Order of Preference by Similarity to Ideal Solution), FAHP (Fuzzy Analytical Hierarchy Process) and GRA (Grey Relational Analysis) were also used in this problem This paper consists of three modules: first, the blind spots of the existing body structure dimension used in heavy vehicles were studied and the optimal design parameters were determined by using ANOVA and TOPSIS methodologies; next, the weights of the design parameters were calculated using FAHP method. Finally, GRA-based Multi Criteria Decision Making (MCDM) approach has been used to rank the vehicle body structures. The proposed model has been implemented in a transport corporation to compare four different types of body structures and concluded that the body structure which was built by an outsourced body builder is having a smaller area of blind spot and optimal design parameters as well.
\end{abstract}

\section{KEY WORDS}

blind spot; Grey Relational Analysis; Fuzzy Analytical Hierarchy Process; multi-objective optimization;

\section{INTRODUCTION}

Good driver's visibility is essential for safe road traffic [1]. Many accidents are caused by drivers of larger vehicles who are not aware that other road users are very close to or beside their own vehicle in the blind spots [2]. A blind spot in a vehicle is the area around the vehicle that cannot be directly observed by the driver while driving. The heavy vehicle drivers cannot see certain areas on the roadway in their front, behind the vehicle and on either side of the vehicle. Figure 1 reveals the area of the blind spot existing in a heavy transport vehicle.

The visibility does not only depend on the individual driver's vision condition but also on the design of the driver's seat and the rear-view mirror. These designs are directly related to the area of the blind spot in front and on the sides of the vehicle. The driver's forward visibility or the front end blind spots are influenced by many design criteria such as vehicle body structure, human anthropometric data, road geometry, etc.

In the driver's seat design as well, the reduction of blind spots has to be considered. Among the main factors to be considered for the driver's seat design like height of the seat from platform, total seat height, distance from seat backrest to windscreen glass and distance from seat backrest to the steering wheel centre; to reduce the blind spots, the distance between seat backrest and windscreen glass has attracted major importance[3]. A large enough blind spot in the rear or sides of the heavy vehicle can completely hide a small pedestrian, a small motor-cycle or even a full vehicle. Because, blind spots hide them before making such manoeuvres on roads while turning, reversing, changing lanes, or while overtaking other vehicles. This places the driver in a risky situation resulting sometimes in untoward incidents and accidents. 


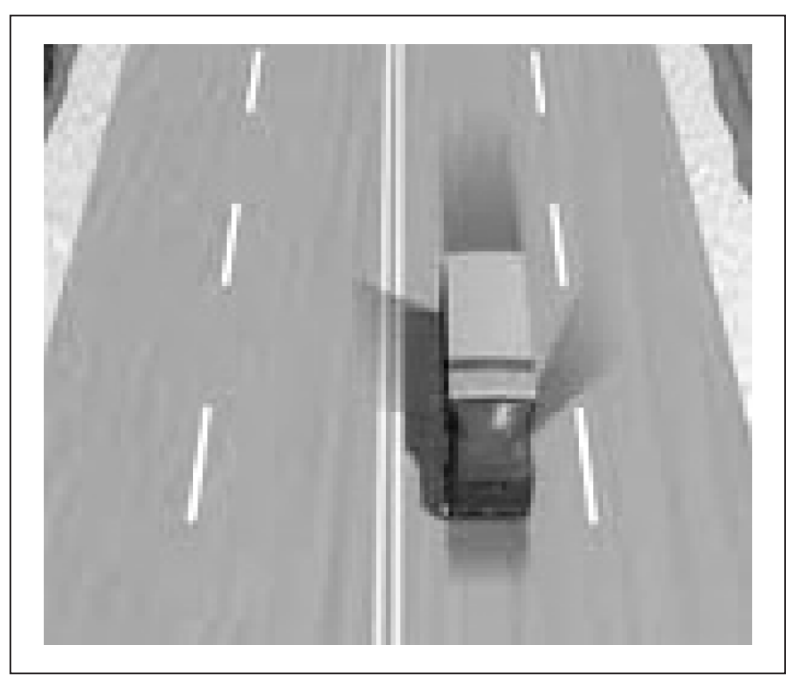

Figure 1 - The blind spot area

In this paper the following two important designs have been considered:

- Design parameters involved in the driver's seat design,

- Design parameters involved in rear-view mirror design.

The remaining part of this paper is organized as follows: Section 2 reviews the literature related to the study; the development of model is explained in Section 3. Section 4 reveals the case study and finally, Section 5 concludes the study and outlines some future research directions.

\section{LITERATURE REVIEW}

\subsection{Review on optimization of design parameters of driver's seat design}

The driver's seat is the only place from where the driver is driving the vehicle. A well designed driver's seat should assure the driver's satisfaction and less fatigue by way of its safety aspects, comfort and versatility. An attempt is made to overcome the blind spot in front of the driver by optimizing the parameters used in the design of the driver's seat of heavy public transport vehicles. To design the seat the following criteria such as driver's anthropometric data, driver's visibility, driver's reach to the controls and size, shapes and deflection of the seat are considered [4]. The driver's seat design should be such as to overcome the problems of blind spots with respect to the driver's visibility while sitting in the driver's seat. Thus, the design of the driver's seat is a very vital point to be considered in any automobile vehicle. In the passenger vehicles, the driver allows the passengers to alight and board the buses at the stops and then moves the vehicles to the next stop. Many of the stops are located in the densely populated residential areas. Normally, the drivers concentrate more on passenger activities and are totally unaware of what is happening in front of the vehicle in the blind spot area which may lead to fatal accidents.

The fatigue is directly related to the design of the driver's seat. The driver cannot depend on his feet to assist with the support of the body like sitting in a chair traditionally since they use their legs to operate the pedals. Hence, the seat design should give assurance to the driver's body balance and control [5]. The driver's fatigue is a prime factor in commercial vehicle accidents [6]. It is evident that the poorly designed seats will cause fatigue in drivers and in turn the fatigue will make the driver drive without the concentration on the blind spots [7]. Even if the driver drives under the influence of fatigue, they should be able to manage and control the blind spot and the design should support this effect. Gundogdu [8] presented genetic algorithm based optimization of parameters to design the car seat in order to improve the driver's performance. Javier et al. [3] presented a design methodology for the driver cabin of sports vehicles applying the ergonomic module.

\subsection{Review on optimization of design parameters of rear-view mirror}

For the blind spots behind and on either side of the heavy vehicle, the role of the rear-view mirrors is very important. The adjustment and installation or positioning of mirrors with larger fields-of-view will be helpful in reducing the blind spots. While considering the installation of mirrors, the distance between the driver and the pillar or frame structure to the left and right side of the front body structure, the driver's eyesight height while seated in the driver's seat from the platform, and the centre height of the mirror from the ground level are all important data.

Burger [9] evaluated and reported the rear vision systems of twelve passenger vehicles and three trucks under real-world driving conditions. Also, a secondary study used the expert judgment techniques to obtain estimates of rear scene zone criticality. Thomas et al. [10] reviewed the safety aspects involved in the use of rear-view mirrors and discussed the research directions. Moreover, major accidents were caused when the target vehicle appeared in the driver's blind spot during lane change or crowded urban travelling and the driver did not carefully observe the approaching vehicle from the rear and side mirrors [11]. Jan and Pieter [12] studied the use of cameras to support drivers under low visibility conditions or/and in the blind spot area.

Optimizing the parameters of a vehicle at the design stage was done by using neural network [13]. Hughes et al. [14] discussed the factors that motivate the use of electronic vision systems such as wide-an- 
gle and fish-eye camera technologies in vehicles. The benefits of using wide-angle lens camera systems to minimize the vehicle's blind-zones were described. An overview of the ongoing research in the blind zone area has been provided as well as the proposed ideas to realize the images and objects in the blind zone using RFID and Bluetooth technology [15]. The design parameters involved in the design and installation of rear-view mirrors should be in optimal conditions in such a way as to overcome the problems of blind spots on the either side of the vehicle. Cho and Han [16] investigated that the driver's vision is the most critical factor for an unusual driving situation. Martijn et al. [17] presented the systematic approach when designing a new lane change support system for vehicles using virtual reality simulation and gaming principles. The mock-up system consisted of three flat screens that offered rear-view mirror functionality. Kim et al. [18] studied the surface flow and wake structure around an automotive external rear-view mirror and demonstrated the visualizations over the mirror housing surface and the driver side vehicle skin. The computer-based simulation method is also used to detect and warn of objects present within the blind spots of automobiles [1]. Gaetano et al. [19] analysed the main variables involved in the visual activity of the driver of motor vehicles while driving to make appropriate corrective actions to achieve road safety. Through a survey a number of variables within the road environment were collected and analysed by using Fuzzy Logic and Artificial Neural Network.

\subsection{Review of optimization techniques}

Wu et al. [20] evaluated the safety of vehicles used in a coal mine by using TOPSIS. The criteria weights were computed based on the grey entropy measurement. Qiong et al. [21] proposed an intelligent decision support system (IDSS) to evaluate the road safety performance in the European countries. To develop the IDSS, an improved hierarchical fuzzy TOPSIS model was used. The experts' knowledge was incorporated in the proposed model. Moataz and Julian [22] evaluated the user's perception of bus transit services by using a review. The gap in the perceptions held by the current and potential users was also measured. First an AHP model was developed to measure the user preference. Then a weighted perception index (WPI) of both preference and satisfaction was developed through a multi-criteria model. Finally, a multivariate analysis of variance (MANOVA) was conducted to identify the level of variation in the perception of both current and potential users of bus service quality. The blind spot area was optimized using the COPRAS (Complex Proportional Assessment of alternatives) technique [23]. Different weights computation methods such as AHP,
FARE (Factor Relationship) method and Entropy Measurement were compared.

The aim of this work is to optimize the blind spots for heavy transport vehicles by optimizing the design parameters used for the design of driver's seat and rear-view mirror. First, the influencing parameters to design the driver's seat and rear-view mirror in order to reduce the blind spot areas were identified by using ANOVA and TOPSIS methodologies. Then GRA-based MCDM was developed to rank the vehicle body structures by using a case study conducted in the transport corporation of Tamilnadu, India.

\section{MODEL DEVELOPMENT}

The reduction of blind spots in heavy vehicles is achieved in two phases. The area of the blind spot in the front and on both sides of the vehicle is reduced through the optimization of design parameters involved in driver seat and the rear-view mirror. The tools and techniques used in this study are ANOVA, TOPSIS, GRA and FAHP. Figure 2 depicts the proposed framework followed in this paper.

\subsection{ANOVA}

Analysis of Variance (ANOVA) is the analysis of variation in an experimental outcome and especially of a statistical variance in order to determine the contributions of the given factors or variables of the variance [24]. It is determined by assuming that the data are normally distributed and the variances of dependent variable are equal in all populations. ANOVA measures two sources of variation in the data and compares their relative sizes such as variation between groups and variation within groups.

Variation between groups $=\left(\overline{X_{i}}-\bar{x}\right)^{2}$

Variation within groups $=\left(x_{i j}-\bar{x}_{i}\right)^{2}$

where $\bar{x}=$ mean for entire dataset, $x_{i j}=$ value for individual $j$ in group $i$ and $\overline{x_{i}}=$ mean for group $i$

Then the standard deviation $\left(s_{i}\right)$ is calculated using equation (3).

$s_{i}=\sqrt{\frac{\sum_{i j}^{n}\left(x_{i j}-\overline{X_{i}}\right)^{2}}{n-1}}$

where $n=$ number of individuals in groups $i \& j$

Next, the sums of the squared differences which are called sums of squares (SS) are calculated using equation (4). The total sum of squares (SST) is equal to the Error Sum of squares (SSE) plus the sum of squares among groups (SSG).

$S S T=S S E+S S G$

where

$\mathrm{SST}=\sum_{\mathrm{obs}}\left(\overline{X_{i j}}-\bar{x}\right)^{2}$ 
$\mathrm{SSE}=\sum_{o b s}\left(\bar{X}_{i j}-\bar{X}_{i}\right)^{2}$

$S S G=\sum_{a b s}\left(\overline{x_{i}}-\bar{x}\right)^{2}$

After the determination of SS, the mean square (MS) will be determined using equation (8). The mean squares are equal to the ratio between the sum of squares and degrees of freedom (DF).

$M S=\frac{S S}{D F}$

Finally, the $F$ statistic value is calculated using equation (9). It is the ratio of the average variability among groups divided by the average variability within groups

$F=\frac{M S G}{M S E}$

where MSG is the mean square among groups and MSE is the error mean square.

This $F$ value is compared with the $F$ value obtained from the statistical table. If the observed value is more than the theoretical value, then that is considered as influencing criteria.

\subsection{TOPSIS}

Hwang and Yoon [25] developed the TOPSIS based on the concept of the distance of the alternative from the positive and negative ideal solutions. The reason behind this concept is that the most preferred alternative should simultaneously have the shortest distance from the positive ideal solution and the farthest distance from the negative ideal solution, which also certainly reflects the rationale of human choice. The steps used in TOPSIS process are listed below:

Step 1 - Construction of evaluation matrix: An evaluation matrix was constructed using the alternatives and the criteria

$X=\left(X_{i j}\right)$

where $i=1,2, \ldots . . m$ criteria and $j=1,2,3, \ldots . . n$ alternative

Step 2 - Determination of normalized decision matrix: The data of influencing criteria are normalized using equation (11).

$$
\Gamma_{i j}=\frac{X_{i j}}{\sqrt{\sum_{i \& j=1}^{i=m \& j=n}\left(X_{i j}\right)^{2}}}
$$

where, $X_{i j}$ is the $\mathrm{i}^{\text {th }}$ criterion for $\mathrm{j}^{\text {th }}$ alternative

Step 3 - Calculation of the weighted normalized decision matrix: The weighted normalized decision matrix $\left(\mathrm{W}_{\mathrm{WNM}}\right)$ is determined by multiplying the normalized decision matrix by its associated weights $\left(\mathrm{W}_{\mathrm{ij}}\right)$ which are calculated using equation (12).

$$
\begin{aligned}
& W_{\text {WNMA }}=W_{i j} \cdot X_{i j} \\
& \text { where, } W_{i j}=\sqrt[10]{\frac{\sum \pi\left(X_{i j}\right)}{\pi\left(X_{i j}\right)}}
\end{aligned}
$$

Step 4 - Building of positive and negative ideal solutions: The positive ideal solution corresponds to the set of best or maximum values of each column. Conversely, the negative ideal solution constitutes the set of worst or minimum values of each column of the evaluation matrix.

Step 5 - Determination of separation measures: The separation measures $\left(\mathrm{Ci}^{*}\right)$ were calculated from the ideal solution using equation (13).

$C_{i}^{*}=\frac{S_{i}}{S_{i}^{*}+S_{i}}$

where

$S_{i}^{*}=\sqrt{\sum_{j}\left(V_{j}^{*}-V_{i j}\right)^{2}}$

and

$S_{i}=\sqrt{\sum_{i}\left(V_{j}^{-}-V_{i j}\right)^{2}}$

where $\mathrm{V}_{\mathrm{j}}^{*}=$ positive ideal solution; $\mathrm{V}_{\mathrm{j}}^{-}=$negative ideal solution; $\mathrm{V}_{\mathrm{ij}}=$ weighted normalized value for $\mathrm{i}^{\text {th }}$ criterion for $\mathrm{j}^{\text {th }}$ alternative; $\mathrm{i}=1,2, \mathrm{~m}$ and $\mathrm{j}=1,2, \mathrm{n}$

Step 6: Ranking of alternative: The alternatives are then ranked based on their closeness to the ideal solution $\left(\mathrm{C}_{\mathrm{i}}^{*}\right)$

\subsection{Grey Relational Analysis (GRA)}

Deng [26] applied the grey theory that provides an effective means to solve problems containing uncertainty. It was suitable for decision-making under more uncertain environments. The grey system theory consists of the following procedural steps:

- (i) Collection of data;

- (ii) Data pre-processing;

- (iii) Calculation of the grey relational coefficient;

- (iv) Calculation of the grey relational grade (GRG). The collected data are pre-processed (normalized) by using equations (16) and (17). In the criterion if the larger value is better it can be normalized using equation (16) while for the criterion if the smaller value is better it can be normalized using equation (17).

$X_{i}^{*}(j)=\frac{x_{i}(j)-\min x_{i}(j)}{\max x_{i}(j)-\min x_{i}(j)}$

$X_{i}^{*}(j)=\frac{\max _{i}(j)-x_{i}(j)}{\max x_{i}(j)-\min x_{i}(j)}$

where, $i=1,2, \ldots . m$ (Alternatives); $\mathrm{j}=1,2 \ldots n$ (Criteria).

Then the absolute difference $\left(\Delta_{i}(j)\right)$ between the normalized cell value and the corresponding referential series value was determined by using equation (18).

$\Delta_{i}(j)=\operatorname{abs}\left(X_{o}^{*}(j)-X_{i}^{*}(j)\right.$

where $X_{o}^{*}(j)=$ referential series value of $j^{\text {th }}$ criterion; $X_{i}^{*}(j)=$ normalized cell value of $j^{\text {th }}$ criterion.

From the normalized data, the grey relational coefficient is calculated to express the relationship between 


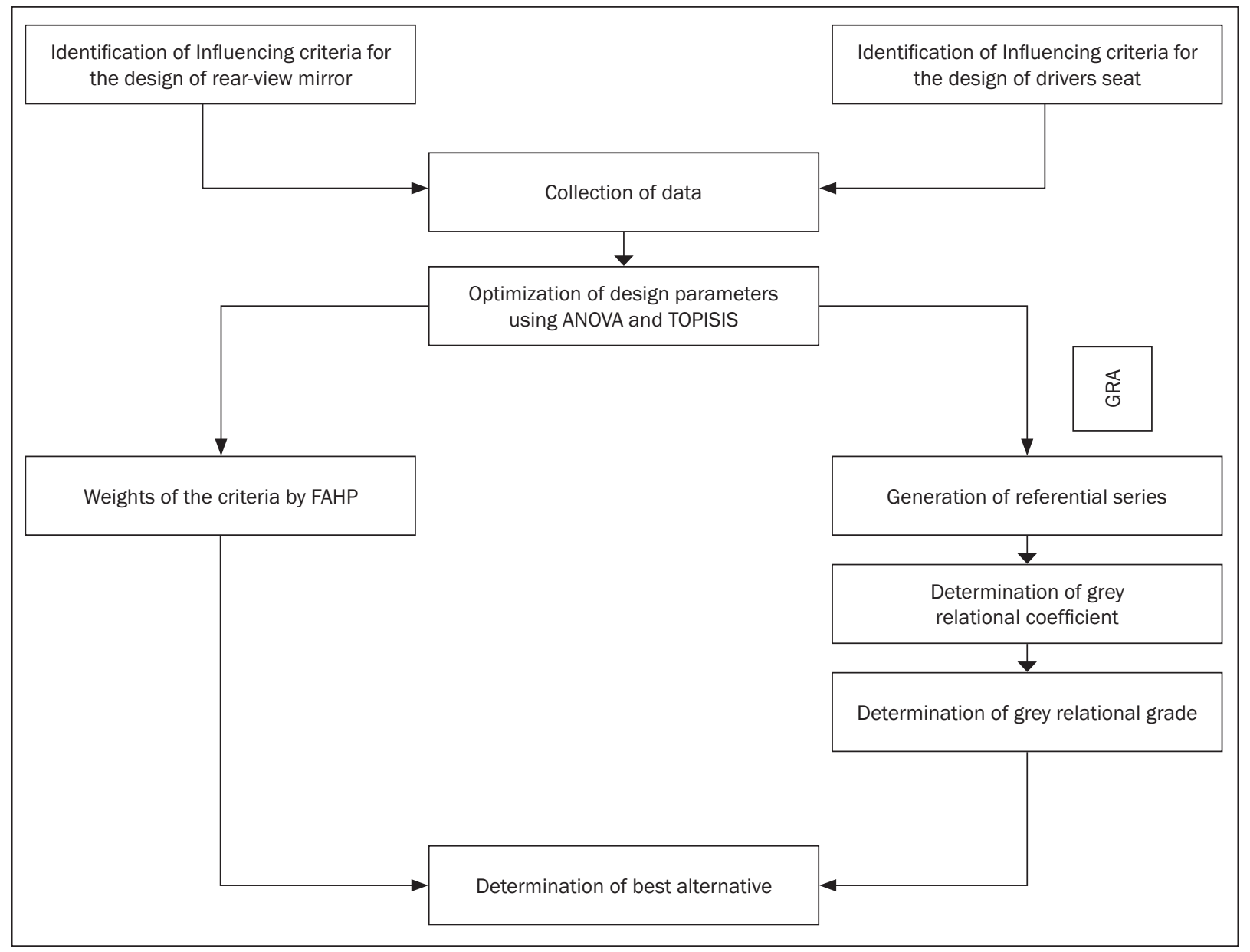

Figure 2 - Proposed framework

the best and the actual results by using the following equation (19).

$\gamma_{i}(j)=\frac{\Delta \min +\xi \Delta \max }{\Delta_{i}(j)+\xi \Delta \max }$

where $\Delta \min =\min _{i} \min _{j} \Delta_{i}(j) ; \Delta \max =\max _{i} \max _{j} \Delta_{i}(j) ;$ and $\xi=$ distinguished coefficient between 0 and 1 .

Finally the grey relational grade (GRG) is calculated using equation (20).

$\Gamma^{\prime} p_{i}=\sum_{j=1}^{n}\left[W_{i}(j) \cdot \gamma_{i}(j)\right]$

where $W_{i}(j)=$ weight of criterion $j$

In this paper the weights of the criterion $W_{i}(j)$ are calculated by FAHP method.

\subsection{FAHP}

In FAHP, the Saaty's [27] analytical hierarchy process is combined with a fuzzy concept. Based on the opinion of the decision maker, the evaluation criteria are compared. The importance of the criteria used for evaluation was collected from the experts. Based on this, first the criteria matrix was formed based on the Saaty's nine point scale which is shown in Table 1.
The pair-wise comparison matrix is called original matrix or criteria matrix which is given by matrix $X_{\text {att }}$ as shown below.

$X_{\text {att }}=\left|a_{i j}\right| ; 1 \leq i, j \leq m$

where, $a_{i j}=$ pairwise comparison of $i^{\text {th }}$ and $j^{\text {th }}$ attribute; $m=$ the number of alternatives.

This was converted into fuzzy original matrix using TFN prescribed by Mohamad et al. [28] which is also shown in Table 1 . The fuzzy number in a fuzzy set can be represented by equation (22).

$F=\{x, \mu F(x)\}, x \in R$

where $F$ is fuzzy set; $x$ is fuzzy number; $R:-\alpha \leq x \leq \alpha$ and $\mu F(x)$ is a continuous mapping from $\mathrm{R}$ in the interval [0, 1]. TFN expresses the relative strength of each pair of elements in the same hierarchy and denoted as TFN $(\mathrm{M})=(\mathrm{I}, \mathrm{m}, \mathrm{u})$ where $\mathrm{I} \leq \mathrm{m} \leq \mathrm{u}$ in which $\mathrm{I}$ is the smallest possible value, $m$ is the most promising value and $u$ is the largest possible value in a fuzzy event. The triangular membership function of $M$ fuzzy number can be described in equation (23) 
P. Pandian, et al.: Development of Fuzzy Based Intelligent Decision Model to Optimize the Blind Spots in Heavy Transport Vehicles

Table 1 - Equivalent triangular fuzzy number for Saaty's nine point scale

\begin{tabular}{||l|c|c||}
\hline \multicolumn{1}{|c|}{ Verbal judgment or preference } & Saaty's scale of relative importance & Triangular fuzzy numbers \\
\hline \hline Extremely preferred & 9 & $9,9,9$ \\
\hline Very strongly to extremely preferred & 8 & $7,8,9$ \\
\hline Very strongly preferred & 7 & $6,7,8$ \\
\hline Strongly to very strongly preferred & 6 & $5,6,7$ \\
\hline Strongly preferred & 5 & $4,5,6$ \\
\hline Moderately to strongly preferred & 4 & $3,4,5$ \\
\hline Moderately preferred & 3 & $2,3,4$ \\
\hline Equally to moderately preferred & 2 & $1,2,3$ \\
\hline Equally preferred & 1 & $1,1,1$ \\
\hline
\end{tabular}

$f(x)=\left\{\begin{array}{lr}0 & x<1 \\ (x-I) /(m-I) I \leq & x \leq m \\ & (u-x) /(u-m) m \leq x \leq u \\ 0 & x>u\end{array}\right.$

The fuzzy original matrix is shown in Table 3. Then the fuzzy original matrix is normalized using equation (24)

$N_{i j}=\frac{a_{i j}}{T_{j}}$

where $a_{i j}$ is the cell value of $i^{\text {th }}$ row and $j^{\text {th }}$ column in the fuzzy original matrix; $1 \leq i, j \leq m$; and $T_{j}=\sum_{i=1}^{m} a_{i j}$

The weights were calculated by converting fuzzy numbers into crisp values by using defuzzification technique. The defuzzification has the capability to reduce a fuzzy to a crisp single-valued quantity. There are seven methods that were used for defuzzification of the fuzzy output functions such as max-membership principle, centroid method, weighted average method, mean-max membership, centre of sums, centre of the largest area and the first of maxima or the last of maxima. In this study, the centroid method was used for defuzzification which is given in equation (25).

Weights (Crisp value) $W i=\frac{\sum_{i-1}^{k} D_{p}^{i} * O^{i}}{\sum_{1}^{k} D_{p}^{i}}$

where $k$ is the number of rules, $O^{i}$ is the class generated by rule i (from $0,1, \ldots . L-1$ ); $L$ is the number of classes and

$D_{P}^{i}=\prod_{i=1}^{n} m_{l i}$

where $n$ is the number of inputs and $m_{l i}$ is the membership grade of feature I in the fuzzy regions that occupies the $\mathrm{i}^{\text {th }}$ rule.

Since the pairwise comparison matrix is formulated based on human judgment, it must ensure that the values collected are the accepted values. To check the

Table 3 - Random Indices

\begin{tabular}{||c|c|c|c|c|c|c|c|c|c|c|c|c||}
\hline $\mathrm{m}$ & 1 & 2 & 3 & 4 & 5 & 6 & 7 & 8 & 9 & 10 & 11 & 12 \\
\hline $\mathrm{RI}$ & 0 & 0 & 0.58 & 0.90 & 1.12 & 1.24 & 1.32 & 1.41 & 1.45 & 1.49 & 1.51 & 1.58 \\
\hline
\end{tabular}
using equation (27)
$C R=\frac{C l}{R l}$

where $\mathrm{Cl}$ is the Consistency Index which is determined using equation (28) and RI are random indices for criterion size ' $m$ '.

$\mathrm{Cl}=\frac{\lambda_{\max }-m}{m-1}$

where $\lambda_{\max }$ is the maximum eigenvalue and $m$ is the number of criteria

RI was approximated by Saaty [27] which is shown in Table 2. If $\mathrm{CR}$ is $<0.10$ the decision maker's pairwise comparison matrix is acceptable.

\section{CASE STUDY}

To prove the effectiveness of the proposed model, a case study has been conducted in a transport division located in the southern part of India. At present, four different types of vehicle bodies are used in that division. They include a body built in the same organization (in-sourcing - IS) and three outsourced (OS -1 , OS - 2 \& OS - 3) bodies. The influencing criteria among three different criteria such as types of buses, behaviour of the drivers and the specifications related to the design of the driver's seat and the rear-view mirror was determined by ANOVA. The specifications are found as the main cause for the issue and variances [27].

\subsection{Determining the influencing variables of driver's seat design}

Based on the experts' opinion, the following data variables such as distance between the driver's seat and platform $(A)$, total seat height $(B)$, distance between seat backrest and windscreen $(C)$ and the distance between seat backrest and steering centre (D) 
Table 3 - Data of influencing criteria for the driver's seat design

\begin{tabular}{||c|c|c|c|c||}
\hline Types of vehicles & $\mathrm{A}(\mathrm{cm})$ & $\mathrm{B}(\mathrm{cm})$ & $\mathrm{C}(\mathrm{cm})$ & $\mathrm{D}(\mathrm{cm})$ \\
\hline \hline IS & 48.5 & 100 & 136 & 62 \\
\hline OS -1 & 53 & 102 & 166 & 64 \\
\hline OS -2 & 49 & 99 & 134 & 63 \\
\hline OS -3 & 49 & 99 & 144 & 66 \\
\hline
\end{tabular}

are identified as the influencing criteria for the design of the driver's seat to optimize the blind spot. The data of influencing criteria for the design of the driver's seat are given in Table 3.

\subsection{Determining the influencing variables of rear-view mirror design}

Similarly, for the rear-view mirror design, the influencing variables are identified using ANOVA [27]. The following data variables such as the distance between the driver and the right side of the body pillar or frame structure $(P)$, the distance between the driver and the left side of the body pillar or frame structure (Q), the distance of the driver's eye right height from the platform $(R)$ and the distance between the centre of the rear-view mirror and the ground level (S) are identified as the influencing criteria for the design and implementation of rear-view mirror in heavy vehicles. The data of influencing criteria for the rear-view mirror design are given in Table 4.

The data of influencing criteria for the design of driver's seat and rear-view mirror which are given in Table 3 and Table 4 are normalized using equation (12). The normalized decision matrix is shown in Table 5.
After that, the weighted normalized decision matrix $\left(W_{W N M}\right)$ is determined using equation (12). Next, the positive ideal solution $\left(V_{j}^{*}\right)$ and negative ideal solution $\left(V_{j}^{-}\right)$are taken from the $W_{W N M}$ and the separation measures are calculated from the ideal solution using equation (13).

\subsection{GRA-based ranking}

The collected data are given in Table 3 and Table 4. These datasets are known as criteria matrix. From the criteria matrix the optimal value for each criterion was taken and these values are known as referential data $\left(X_{\circ}^{*}(j)\right)$. These data are pre-processed (normalized) by using equations (16) and (17). After pre-processing, the values are given in Table 7 . Then the absolute difference between the normalized cell value and the corresponding referential series value was determined by using equation (18).

From the normalized data, the grey relational coefficient is calculated to express the relationship between the best and the actual results by using equation (19) and shown in Table 8.

Next the weight of the criterion $W_{i}(j)$ is calculated by FAHP method.

Table 4 - Data of influencing criteria for the rear-view mirror design

\begin{tabular}{||c|c|c|c|c||}
\hline Types of vehicles & $P(\mathrm{~cm})$ & $\mathrm{Q}(\mathrm{cm})$ & $\mathrm{R}(\mathrm{cm})$ & $\mathrm{S}(\mathrm{cm})$ \\
\hline \hline IS & 34 & 177 & 119 & 204 \\
\hline OS -1 & 34 & 181 & 123 & 240 \\
\hline OS -2 & 34 & 182 & 123 & 224 \\
\hline OS -3 & 36 & 178 & 122 & 242 \\
\hline
\end{tabular}

Table 5 - Normalized decision matrix

\begin{tabular}{|c|c|c|c|c|c|c|c|c||}
\hline \multirow{2}{*}{ Types of vehicles } & \multicolumn{4}{|c|}{ Design of driver's seat } & \multicolumn{4}{c||}{ Design of rear-view mirror } \\
\cline { 2 - 9 } & $\mathrm{A}$ & $\mathrm{B}$ & $\mathrm{C}$ & $\mathrm{D}$ & $\mathrm{P}$ & $\mathrm{Q}$ & $\mathrm{R}$ & $\mathrm{S}$ \\
\hline \hline IS & 0.1248 & 0.2573 & 0.3499 & 0.1595 & 0.537 & 0.2795 & 0.1879 & 0.3222 \\
\hline OS -1 & 0.1364 & 0.2625 & 0.4272 & 0.1647 & 0.0537 & 0.2859 & 0.1943 & 0.3790 \\
\hline OS - 2 & 0.1261 & 0.2547 & 0.3448 & 0.1621 & 0.0537 & 0.2874 & 0.1943 & 0.3538 \\
\hline OS - 3 & 0.1261 & 0.2547 & 0.2547 & 0.1698 & 0.059 & 0.2811 & 0.1927 & 0.3822 \\
\hline
\end{tabular}

Table 6- Separation from ideal alternative

\begin{tabular}{|c|c|c|c|c|c|c|c|c||}
\hline \multirow{2}{*}{} & \multicolumn{4}{|c|}{ Design of driver's seat } & \multicolumn{4}{c|}{ Design of rear-view mirror } \\
\cline { 2 - 9 } & $\mathrm{A}$ & $\mathrm{B}$ & $\mathrm{C}$ & $\mathrm{D}$ & $\mathrm{P}$ & $\mathrm{Q}$ & $\mathrm{R}$ & $\mathrm{S}$ \\
\hline \hline $\mathrm{C}_{\mathrm{i}}^{*}$ & 0.3864 & 0.4029 & 0.5119 & 0.4596 & 0.6348 & 0.4978 & 0.3909 & 0.4290 \\
\hline
\end{tabular}


P. Pandian, et al.: Development of Fuzzy Based Intelligent Decision Model to Optimize the Blind Spots in Heavy Transport Vehicles

Table 7 - Normalized data

\begin{tabular}{|c|c|c|c|c|c|c|c|c||}
\hline \multirow{2}{*}{ Types of vehicles } & \multicolumn{4}{|c|}{ Design of driver's seat } & \multicolumn{4}{c||}{ Design of rear-view mirror } \\
\cline { 2 - 10 } & $\mathrm{A}$ & $\mathrm{B}$ & $\mathrm{C}$ & $\mathrm{D}$ & $\mathrm{P}$ & $\mathrm{Q}$ & $\mathrm{R}$ & $\mathrm{S}$ \\
\hline \hline IS & 1.000 & 0.667 & 0.063 & 0.000 & 0.000 & 1.000 & 0.000 & 0.000 \\
\hline OS - 1 & 0.000 & 0.000 & 1.000 & 0.500 & 0.000 & 0.200 & 1.000 & 0.947 \\
\hline OS - 2 & 0.889 & 1.000 & 0.000 & 0.250 & 0.000 & 0.000 & 1.000 & 0.526 \\
\hline OS - 3 & 0.889 & 1.000 & 0.313 & 1.000 & 1.000 & 0.800 & 0.750 & 1.000 \\
\hline
\end{tabular}

Table 8 - Grey relational coefficient

\begin{tabular}{|c|c|c|c|c|c|c|c|c||}
\hline \multirow{2}{*}{ Types of vehicles } & \multicolumn{4}{|c|}{ Design of driver's seat } & \multicolumn{4}{c||}{ Design of rear-view mirror } \\
\cline { 2 - 10 } & A & B & C & D & P & Q & R & S \\
\hline \hline IS & 1.000 & 0.998 & 0.995 & 0.989 & 0.980 & 1.000 & 0.994 & 0.997 \\
\hline OS - 1 & 0.987 & 0.993 & 1.000 & 0.995 & 0.980 & 0.997 & 1.000 & 1.00 \\
\hline OS - 2 & 0.999 & 1.000 & 0.995 & 0.992 & 0.980 & 0.996 & 1.000 & 0.998 \\
\hline OS - 3 & 0.999 & 1.000 & 0.997 & 1.000 & 1.000 & 0.999 & 0.999 & 1.000 \\
\hline
\end{tabular}

\subsubsection{Weights by FAHP}

The FAHP process starts with the pairwise comparison matrix. Based on the ranking obtained from Table 10, the criteria are compared with each other using the Satty's nine point scale (Table1). The crisp matrix is converted into fuzzy matrix using triangular fuzzy numbers recommended by Mohamad et al. [28]. The equivalent triangular fuzzy number for Saaty's nine point scale is shown in Table 1. By using it, the criteria matrix is converted into fuzzy criteria matrix which is shown in Table 9 (a) and 9 (b). The fuzzy criteria matrix was normalized and shown in Table 10 (a) and 10 (b).

The fuzzy numbers are defuzzified using equation (25) and the weights are obtained (Table 10 (a) and 10 (b)). The Consistency Ratio for this proposed FAHP model is calculated using equation (27) and found as 0.0755 for the driver's seat design and as 0.0873 for the rear-view mirror design. Both are less than 0.1 and so these models are acceptable.

\subsubsection{Results and discussion}

The weights from Table 10 (a) and 10 (b) are used to determine the GRG using equation (20) and given in Table 11 and Figure 3. The overall GRG is determined by computing the average of both GRG values. From the overall GRG, the best alternative is selected. From Table 15 and Figure 3 it is understood that OS - 3 vehicle has the higher GRG values followed by IS, OS-2 and OS-1 body built vehicles. Hence the vehicle body built by the third outsourced body building unit features the minimum blind spot.

With the improved dimensions, in OS -3 vehicles the area of the blind spot is reduced to 4.198 square metres [28] from 5.03 square metres as in IS vehicles.

\section{CONCLUSION}

This paper discusses the elimination of blind spots in the front and on the sides of heavy vehicles

Table 9 (a) - Fuzzy pairwise comparison matrix for the driver's seat design

\begin{tabular}{||c||c|c|c|c|c|c|c|c|c|c|c|c||}
\hline & \multicolumn{4}{|c|}{ A } & \multicolumn{3}{c|}{ B } & \multicolumn{3}{c|}{ C } & \multicolumn{3}{c||}{ D } \\
\hline \hline A & 1.00 & 1.00 & 1.00 & 3.00 & 4.00 & 5.00 & 1.00 & 0.50 & 0.33 & 1.00 & 2.00 & 3.00 \\
\hline B & 0.33 & 0.25 & 0.20 & 1.00 & 1.00 & 1.00 & 0.20 & 0.17 & 0.14 & 1.00 & 0.50 & 0.33 \\
\hline C & 1.00 & 2.00 & 3.00 & 5.00 & 5.99 & 6.93 & 1.00 & 1.00 & 1.00 & 2.00 & 3.00 & 4.00 \\
\hline D & 1.00 & 0.50 & 0.33 & 1.00 & 2.00 & 3.03 & 0.50 & 0.33 & 0.25 & 1.00 & 1.00 & 1.00 \\
\hline Total & 3.33 & 3.75 & 4.54 & 10.00 & 12.99 & 15.96 & 2.70 & 2.00 & 1.72 & 5.00 & 6.50 & 8.33 \\
\hline
\end{tabular}

Table 9 (b) - Fuzzy pairwise comparison matrix for the rear-view mirror design

\begin{tabular}{|c|c|c|c|c|c|c|c|c|c|c|c|c||}
\hline & \multicolumn{4}{|c|}{$\mathrm{P}$} & \multicolumn{3}{c|}{$\mathrm{Q}$} & \multicolumn{3}{c|}{$\mathrm{R}$} & \multicolumn{3}{c||}{$\mathrm{S}$} \\
\hline \hline $\mathrm{P}$ & 1.00 & 1.00 & 1.00 & 1.00 & 2.00 & 3.00 & 4.00 & 5.00 & 6.00 & 2.00 & 3.00 & 4.00 \\
\hline $\mathrm{Q}$ & 1.00 & 0.50 & 0.33 & 1.00 & 1.00 & 1.00 & 3.00 & 4.00 & 5.00 & 1.00 & 2.00 & 3.00 \\
\hline $\mathrm{R}$ & 0.25 & 0.20 & 0.17 & 0.33 & 0.25 & 0.20 & 1.00 & 1.00 & 1.00 & 0.33 & 0.25 & 0.20 \\
\hline $\mathrm{S}$ & 0.50 & 0.33 & 0.25 & 1.00 & 0.50 & 0.33 & 3.00 & 4.00 & 5.00 & 1.00 & 1.00 & 1.00 \\
\hline Total & 2.75 & 2.03 & 1.75 & 3.33 & 3.75 & 4.53 & 11.00 & 14.00 & 17.00 & 4.33 & 6.25 & 8.20 \\
\hline
\end{tabular}


Table 10 (a) - Fuzzy normalized matrix for the driver's seat design

\begin{tabular}{||c|c|c|c|c|c|c|c|c|c|c|c|c|c||}
\hline & \multicolumn{3}{|c|}{ A } & \multicolumn{3}{c|}{ B } & \multicolumn{3}{c|}{ C } & \multicolumn{3}{|c|}{ D } & Weights \\
\hline \hline A & 0.30 & 0.27 & 0.22 & 0.30 & 0.31 & 0.31 & 0.37 & 0.25 & 0.19 & 0.20 & 0.31 & 0.36 & 0.2834 \\
\hline B & 0.10 & 0.07 & 0.04 & 0.10 & 0.087 & 0.06 & 0.07 & 0.08 & 0.08 & 0.20 & 0.08 & 0.04 & 0.0860 \\
\hline C & 0.30 & 0.53 & 0.66 & 0.50 & 0.46 & 0.44 & 0.37 & 0.50 & 0.58 & 0.40 & 0.46 & 0.48 & 0.4745 \\
\hline D & 0.30 & 0.13 & 0.07 & 0.10 & 0.15 & 0.19 & 0.19 & 0.17 & 0.15 & 0.20 & 0.15 & 0.12 & 0.1604 \\
\hline
\end{tabular}

Table 10 (b) - Fuzzy normalized matrix for the rear-view mirror design

\begin{tabular}{||c|c|c|c|c|c|c|c|c|c|c|c|c|c||}
\hline & \multicolumn{3}{|c|}{$\mathrm{P}$} & \multicolumn{3}{|c|}{$\mathrm{Q}$} & \multicolumn{3}{c|}{$\mathrm{R}$} & \multicolumn{3}{|c|}{$\mathrm{S}$} & Weights \\
\hline \hline $\mathrm{P}$ & 0.36 & 0.49 & 0.57 & 0.30 & 0.53 & 0.66 & 0.36 & 0.36 & 0.35 & 0.46 & 0.48 & 0.49 & 0.4588 \\
\hline $\mathrm{Q}$ & 0.36 & 0.25 & 0.19 & 0.30 & 0.27 & 0.22 & 0.27 & 0.29 & 0.29 & 0.23 & 0.32 & 0.37 & 0.2807 \\
\hline $\mathrm{R}$ & 0.09 & 0.10 & 0.10 & 0.10 & 0.07 & 0.04 & 0.09 & 0.07 & 0.06 & 0.08 & 0.04 & 0.02 & 0.0755 \\
\hline $\mathrm{S}$ & 0.18 & 0.16 & 0.14 & 0.30 & 0.13 & 0.07 & 0.27 & 0.29 & 0.29 & 0.23 & 0.16 & 0.12 & 0.2098 \\
\hline
\end{tabular}

which is an important aspect of road safety. An intelligent-based novel hybrid multi-criteria optimization model was proposed in the reduction of blind spot area in heavy transport vehicles. GRA (Grey Relational Analysis) method is used to rank the vehicle body structures. ANOVA was used to identify the influencing criteria among the three such as the types of buses, types of drivers, and the specifications related to the design and implementation of the driver's seat and rear-view mirrors. Then TOPSIS was used to prioritize the criteria among the specifications. Finally,
GRA-based decision model was developed to select the best alternative. In the model FAHP method was combined with GRA. The model was tested on a case study and the effectiveness of the model was proven. In this research the blind spot area in the front and on the sides of the vehicles was considered. By using the parameters determined using the developed model nearly $20 \%$ of the blind spot was eliminated. This was proven by a case study.

Table 11 - GRG and ranking of vehicle

\begin{tabular}{|c|c|c|c|c|c|c|c|c||}
\hline \multirow{2}{*}{$\begin{array}{c}\text { Types of } \\
\text { vehicles }\end{array}$} & \multicolumn{3}{|c|}{ Design of driver's seat } & \multicolumn{2}{c|}{ Design of rear-view mirror } & \multicolumn{2}{c||}{ Overall } \\
\cline { 2 - 11 } & \multicolumn{2}{|c|}{ GRG } & Rank & \multicolumn{2}{c|}{ GRG } & Rank & GRG & Rank \\
\hline \hline IS & $\Gamma_{1}$ & 0.99589 & 3 & $\Gamma_{1}$ & 0.99009 & 3 & 0.99299 & 2 \\
\hline OS -1 & $\Gamma_{2}$ & 0.99503 & 4 & $\Gamma_{2}$ & 0.99028 & 2 & 0.992655 & 4 \\
\hline OS -2 & $\Gamma_{3}$ & 0.99595 & 2 & $\Gamma_{3}$ & 0.98981 & 4 & 0.99288 & 3 \\
\hline OS -3 & $\Gamma_{4}$ & 0.99798 & 1 & $\Gamma_{4}$ & 0.99969 & 1 & 0.998835 & 1 \\
\hline
\end{tabular}

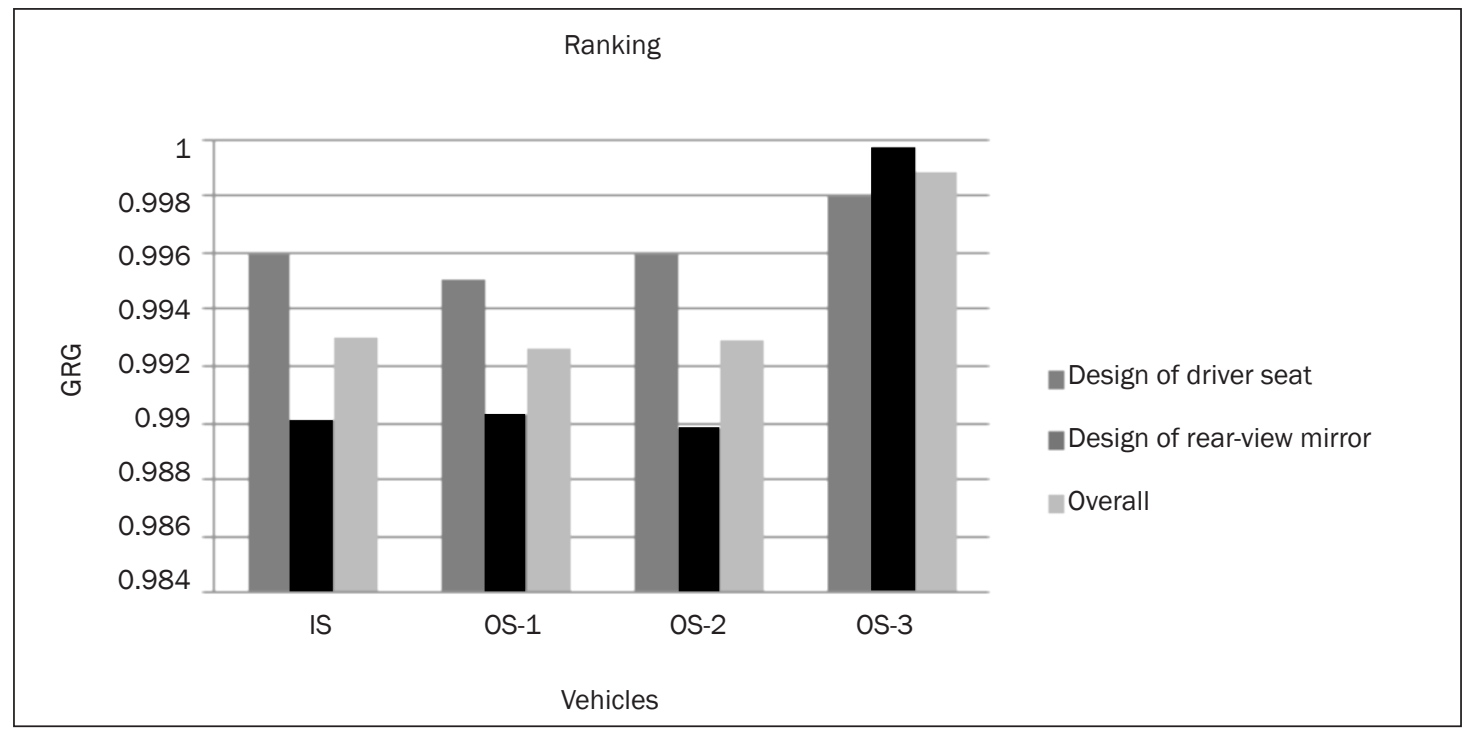

Figure 3 - GRG and ranking of vehicles 
A decision support system can be developed using the proposed model as model base to optimize the design parameters for the reduction of blind spots.

\section{REFERENCES}

[1] Hatamleh H (Moh'd Said), Sharadqeh AAM, Alnaser AM, Alheyasat O, Abu-Ein AA-K. Computer simulation to detect the blind spots in automobiles. Int J Comput Sci Issues. 2013;10 (1):453-456.

[2] Olejnik K. Estimation of the need for harmonization of technical demands for vehicles used in transit countries to decrease threats made by the accidents, presented in the selected examples. Transport. 2008;23(1):78-81.

[3] Sanchez-Alejo FJ, Alvarez MA, Holgado NF, Lopez JM. Defining the ergonomic parameters of the driver's seat in a competition single-seater. Int J Vehicle Des. 2011;55(2/3/4):139-161.

[4] Ahmadian M, Boggs C. Safety effects of operator seat design in large commercial vehicles. Final Report Safety IDEA Project; 2005.

[5] Carrier R. Ergonomic study of the driver's work station in urban buses. Canadian Urban Transit Association Publishers; 1992.

[6] Shen W, Vertiz A. Redefining seat comfort, SAE Paper. 1997;970597.

[7] Park S, Lee Y, Nahm Y, Lee J, Kim J. Seating physical characteristics and subjective comfort: Design considerations. SAE Paper. 1998;980653.

[8] Gundogdu O. Optimal seat and suspension design for a quarter car with driver model using genetic algorithms. Int J Ind Ergon. 2007;37(4):327-332.

[9] Burger W. Evaluation of innovative passenger car and truck rear vision system. SAE paper. 1974;740965.

[10] Ayres T, Li L, Trachtman D, Youn D. Passenger-side rear-view mirrors: driver behavior and safety. Int J Ind Ergon. 2005;35:157-162.

[11] Huang S-J, Chao S-T. A new lateral impact warning system with grey prediction. P I Mech Eng D-J Aut. 2010;224(3):285-297.

[12] van Erp JB, Padmos P. Image parameters for driving with indirect viewing systems. Ergonomics. 2003;46(15):1471-1499.

[13] Dyakov I. The problems of optimal design in the automotive industry. Transport. 2013;28(3):290-294.

[14] Hughes C, Glavin M, Jones E, Denny P. Wide-angle camera technology for automotive applications: A review. Intell Transport Sys. 2009;3(1):19-31.

[15] Lakshmi S, Wahida Banu RSD. Efficient realisation and rendering of images in blind zone. J Comput Eng. 2010;1:1-5.
[16] Cho YH, Han BK. Application of slim a-pillar to improve driver's field of vision. Int J Auto Techn. 2010;11(4):517524.

[17] Tideman M, van der Voort MC, van Arem B. A new scenario based approach for designing driver support systems applied to the design of a lane change support system. Transport Res C. 2010;18:247-258.

[18] Kim JH, Park BH, Han YO. Surface flow and wake characteristics of automotive external rear-view mirror. P I Mech Eng D-J Aut. 2011;225(12):1605-1613.

[19] Bosurgi G, D'Andrea A, Pellegrino O. What variables affect to a greater extent the driver's vision while driving?, Transport. 2013;28(4):331-340.

[20] Wu L, Yang Y , Jing G. Technique for order preference by similarity to Ideal solution (TOPSIS) for safety synthetic evaluation on coal mine transportation system. Prog Saf Sci Technol 2006;6:87-91.

[21] Bao Q, Ruan D, Shen Y, Hermans E, Janssens D. Improved hierarchical fuzzy TOPSIS for road safety performance evaluation. Know Based Syst. 2012;32:84-90.

[22] Mahmoud M, Hine J. Using AHP to measure the perception gap between current and potential users of bus services. Transport Plan Techn. 2013;36(1):4-23.

[23] Pitchipoo P, Vincent DS, Rajini N, Rajakarunakaran S. COPRAS decision model to optimize blind spot in heavy vehicles: A comparative perspective. Proce Engg.2014;97:1049-1059.

[24] Arias-Castro E, Candes EJ, Plan Y. Global testing under sparse alternatives: ANOVA, multiple comparisons and the higher criticism. Ann Stat. 2011;39(5):2533-2556.

[25] Hwang CL, Yoon K. Multiple attribute decision making: Methods and applications. New York: Springer-Verlag; 1981.

[26] Deng JL. Introduction to grey system. J Grey Sys. 1989;1(1):1-24

[27] Thomas L. Saaty. How to make a decision: the analytic hierarchy process. Eur J Oper Res. 1990;48(1):9-26.

[28] Vincent DS, Pitchipoo P, Rajakarunakaran S. Elimination of blind Spots for heavy transport vehicles by driver seat design. Int Conf Adv Manuf Auto, Kalasalingam University, India, March 28-30, 2013.

[29] Mohamad Ashari Alias, Siti Zaiton Mohd Hashim, Supiah Samsudin. Using fuzzy analytic hierarchy process for southern Johor river ranking, Int J Adv Soft Comput Appl. 2009;1(1):62-76. 